\title{
Are Mandatory Institutional Emails for Manuscript Submission an Unfair and Discriminatory Policy?
}

\author{
Jaime A. Teixeira da Silva \\ Independent researcher
}

\section{CORRESPONDENCE}

Jaime A. Teixeira da Silva

P. O. Box 7, Miki-cho post office, Ikenobe 3011-2, Kagawa-ken, 761-0799, Japan

E-mail: jaimetex@yahoo.com

\section{ARTICLE HISTORY}

Received: October 10, 2021 Accepted: December 29, 2021

\begin{abstract}
With increasing cases of fraud in submission, peer review, and publication processes, some by authors with fake identities and who use concocted emails, including the use of web-based emails, editors and publishers are looking for ways to try and stem the tide of fraud. In some journals, editors and publishers mistakenly believe that this might be possible by implementing a policy that mandates submitting authors to have an institutional email. However, this may be discriminatory at various levels, the most obvious of which is unfairness, i.e., no right to "entry" to a journal based exclusively on the type of email used, even more so when the submitting author is not fake. Such policies might, very ironically, even violate stated journal or publisher policies on discrimination and inclusivity. Editors and publishers that employ such tactics, as a way to attempt to reduce fraudulent submissions, need to rethink this potentially discriminatory strategy. In a publishing world that is becoming increasingly litigious, it would not be surprising if legal action would one day be taken against a journal or publisher by a valid author using a web-based email such as @gmail.com, @yahoo.com, or @163.com, but who may have been unfairly barred entry to that journal based on such a policy. Two real case examples are provided, Tumor Biology, a struggling journal published by IOS Press, and Journal of Business Ethics, a journal published by Springer Nature.
\end{abstract}

Keywords: accountability, corresponding author, fairness, responsibility, transparency, verification

Many academics employ public or free web-based emails such as @gmail.com, @yahoo.com,@163.com,@rediffmail.com,@protonmail.com etc., out of convenience (e.g., large storage capacity, ability to transfer large files etc.), including authors with institutional emails. ${ }^{1}$ It is also not uncommon for academics affiliated with research institutes to employ their web-based emails for submission to journals, and a POP service can link web-based emails to an institutional email inbox. In those cases, such authors and their web-based emails are perfectly valid forms of communication with corresponding authors. ${ }^{2}$ However, at least two prominent forms of fake authors use fabricated or concocted emails: those that employ unethical stings or hoaxes, ${ }^{3}$ and paper mills that apparently create disposable emails to falsely represent authors. ${ }^{4}$ In those cases, the users 
and emails are invalid, and their use for these activities not only violates all forms of academic publishing integrity, they are blatant acts of fraud that merit criminalization because their intent is to deceive and cause harm or damage (e.g., reputational, financial etc.)..$^{5-7}$ Academic publishing appears to now be awash with fake elements, including fake authors who employ fake identities and emails. ${ }^{8}$

The criminalization of fraudulent authors by publishers, even if their identities are known, might not occur because litigious action by a journal or publisher against academics might set an untested precedent and could even backfire against the publisher, especially if their public image in the academic community is perceived as one of aggression rather than bold and firm action. Consequently, publishers are left with somewhat menial forms of "punishment", such as retractions, when they encounter fake elements. In the case of paper mill-derived papers, or papers linked to stings, even retractions impact none of the true offenders, especially where emails are created by anonymous/ pseudonymous authors or the paper mills themselves, as they can simply ignore a publisher's actions and threats, or nonchalantly turn a blind eye to retractions. Thus, seeking to criminalize such frauds might be impossible if the true identity of such offenders is unknown. Even though there is a higher rate of retraction of non-institutional emails relative to institutional emails, especially from China, as a result of the association with paper mills, a generalization cannot be made due to insufficient data. ${ }^{9}$

Currently, publishers have limited tools at their disposal to deal with fraudulent entities, even more so masked, anonymous, and pseudonymous entities who make mockery of the submission process and editorial and publication system. Perhaps unconscientiously, as a reactionary response to those threats, publishers are imposing layer after layer of submission and ethical requirements, with guidelines that sometimes represent manuals of rules that are pages long, and that incorporate excessive details among the fine print that perhaps some authors might not be fully aware of, but that binds them ethically and legally. This has led, and continues to lead, to a heightened state of 'militarization' (i.e., forced, non-optional regulations) of the entire publication process, from submission to publication, and beyond, ${ }^{10}$ ultimately fraying authors' rights if they are not allowed to, or able to, fairly challenge those mandatory instructions. ${ }^{11}$ The same struggle between freedom of choice versus mandatory policies can be observed with the author disambiguation tool, ORCID. ${ }^{12}$

Among the tools and strategies that some publishers are using to stem the tide of fraud is a mandatory requirement for corresponding authors to have institutional emails.
Very broadly, emails within academic publishing can be classed into two categories: institutional emails and webbased (also known as free or public) emails (e.g., @gmail. com,@yahoo.com, @protonmail.com etc.), including locally popular forms (e.g., @163.com, @qq.com etc. in China, or @rediffmail.com in India), as well as culturallysensitive variants of some of these (e.g., @yahoo.co.fr for French-speaking users). In the case of institutional emails, some academics' institutes may set limits to traffic volume, inbox size, folder numbers or even to email access internationally, so it is not uncommon for such academics to also create accounts using web-based emails. In some cases, academics list both an institutional and a web-based email as their contact in a published paper. ${ }^{1}$

Two real-case examples are provided. The first is a journal (Tumor Biology) whose reputation is struggling, partly due to victimization caused by fraudulent peer review. The second example is a perceived "respected" ethics journal, Journal of Business Ethics, which is a Committee on Publication Ethics (COPE) member journal and publisher. The Tumor Biology instructions for authors state: "Important note: The journal does not accept submissions from authors using nondescript, anonymous email addresses (e.g., yahoo.com, gmail.com, 163.com, rediffmail.com, sina.com, 126.com, hotmail.com etc.). Institutional email addresses are highly preferred." 13 The Journal of Business Ethics instructions for authors state: "The title page should include: [...] The institutional e-mail address." ${ }^{14}$ In both cases, submissions are completed through Aries Systems' Editorial Manager ${ }^{\circ}$. In other words, submission to Tumor Biology or Journal of Business Ethics is impossible for an academic (i.e., corresponding author) that uses a web-based email address.

A one-size-fits-all approach to dealing with this problem might not yield the desired results, and in this case, where institutional email addresses are mandated, and where web-based emails are barred, good intentions (e.g., to exclude fraudulent or fake authors) may have unintended consequences (e.g., reputational damage) if the ramifications of those actions are not countered or carefully reflected upon. The author has no concrete suggestions as to how this situation could be reformed, except perhaps to open an exception on a case-by-case basis, but this defeats the purpose of an automated submission process and is cumbersome. Any reform that takes place requires editors and publishers to carefully reflect on possible discriminatory actions that may hurt or otherwise victimize perfectly innocent and valid academics. The flow of scholarly ideas and intellectual work should not be hindered by bureaucratic rules that hurt academics. 


\section{CONFLICT OF INTEREST}

The author declares no conflicts of interest of relevance to this topic.

\section{REFERENCES}

1. Kozak M, lefremova O, Szkoła J, Sas D. Do researchers provide public or institutional e-mail accounts as correspondence e-mails in scientific articles? Journal of the Association for Information Science and Technology. 2015;66:2149-2154.

2. Teixeira da Silva JA, Dobránszki J, Van PT, Payne WA. Corresponding authors: rules, responsibilities and risks. The Asian and Australasian Journal of Plant Science and Biotechnology. 2013;7(Special Issue 1):16-20.

3. Teixeira da Silva JA. Assessing the ethics of stings, including from the prism of guidelines by ethics-promoting organizations (COPE, ICMJE, CSE). Publishing Research Quarterly. 2021;37:90-98.

4. Rivera H, Teixeira da Silva JA. Retractions, fake peer review, and paper mills. Journal of Korean Medical Science. 2021;36:e165.

5. Bülow W, Helgesson G. Criminalization of scientific misconduct. Medicine, Health Care and Philosophy. 2019;22:245-252.
6. Dal-Ré R, Bouter LM, Cuijpers P, Gluud C, Holm S. Should research misconduct be criminalized? Research Ethics. 2020;16:1-12.

7. Teixeira da Silva JA. Is there a need for creators of imaginary authors to face legal consequences? Croatian Medical Journal. 2020;61:561-563.

8. Teixeira da Silva JA. Fake peer reviews, fake identities, fake accounts, fake data: beware! AME Medical Journal. 2017:2:28.

9. Liu X-M., Chen X-T. Authors' noninstitutional emails and their correlation with retraction. Journal of the Association for Information Science and Technology. 2021;72:473-477.

10. Teixeira da Silva JA. The militarization of science, and subsequent criminalization of scientists. Journal of Interdisciplinary Medicine. 2016;1:214-215

11. Al-Khatib A, Teixeira da Silva JA. What rights do authors have? Science and Engineering Ethics. 2017;23:947-949.

12. Teixeira da Silva JA. Is mandatory ORCID a violation of an author's freedoms and rights? Serials Review. 2021. (in press) https://doi.org/10.108 0/00987913.2021.2022395

13. Tumor Biology. Author guidelines. https://www.iospress.com/catalog/ journals/tumor-biology (30 September 2021)

14. Journal of Business Ethics. Submission guidelines. Manuscript Presentation. https://www.springer.com/journal/10551/submissionguidelines\#Instructions\%20for\%20Authors_Manuscript\%20Presentation (30 September 2021) 